\title{
Screening of Diabetes and HIV Infection in Newly Diagnosed Pulmonary Tuberculosis Patients
}

\author{
Awais Jamil ${ }^{1}$, Aftab Gohar ${ }^{2}$, Ch. Haider Ali ${ }^{3}$ \\ 1,2,3. House Officer Bahawal Victoria Hospital, Bahawalpur
}

\begin{abstract}
Objective: Aim of the study was to investigate the prevalence of diabetes and HIV infection by screening in newly diagnosed pulmonary tuberculosis patients. Methods: This cross sectional study was conducted in Pulmonology department Bahawal Victoria Hospital Bahawalpur. From 1 June 2018 to 1 June 2019 after taking approval from the institutional ethical committee. Total 159 newly diagnosed pulmonary tuberculosis patients were recruited by non-probability consecutive sampling. Mean and SD was calculated for numerical variables like age , BMI, FBG, Hemoglobin and monthly income. Ferquancy and percentages were calculated for categorical variables like gender, smooking status, educational status, alcohol consumption, prevelance of HIV and diabetes, Ch square test was use to check significant different in PTB and Non PTB patients. P value of $<$ 0.05 was taken as significant. Results: Significant difference was found between age $(p=0.000), B M I(p=0.000)$, FBG $(p=0.000)$, hemoglobin $(p=0.000)$, gender $(p=0.002)$ and alcohol consumption $(p=0.034)$, in groups, except education status $(p=0.090)$ and monthly income $(p=0.068)$. The main outcome variables of this study were HIV infection and diabetes. HIV infection was noted in $3.1 \%(\mathrm{n}=5)$ and $1.9 \%(\mathrm{n}=3)$ patients for PTB and non-PTB group respectively. While, $8.2 \%(n=13)$ and $4.4 \%(n=4)$ patients suffered from diabetes, for both the groups respectively. Conclusion: The results of our study revealed that on screening of newly diagnosed pulmonary tuberculosis patients with HIV infection and diabetes, their prevalence was high as compared to non-pulmonary tuberculosis group. But this difference was statistically non significant (P value 0.474 and 0.166 ).
\end{abstract}

Key words: Pulmonary tuberculosis, Diabetes, HIV infection

DOI: $10.7176 / \mathrm{JMPB} / 55-21$

Publication date:May $31^{\text {st }} 2019$

\section{Introduction}

Diabetes is metabolic disorder. Insulin resistance is the main pathogenesis in development of type 2 diabetes mellitus. Type 2 diabetes is usually affects elderly patients. Type 2 diabetes mellitus is accelerating pandemic throughout the world $\{1\} .230$ million population of the world suffer from diabetes. It has been estimated that this population will reach up to 552 million until $2030\{2\}$. It is recorded that 471 billion USD were spent to treat diabetes in $2012\{3\}$. For the developing countries, it is a great socio economic burden. It is alarming that prevalence of diabetes has significantly risen in past two decades. In 2011 diabetes prevalence was ranging from $7.6 \%$ (5.2 million people) to $11 \%$ in Pakistan and it is expected to reach up to $15 \%$ (14 million) until $2030\{4\}$. Pakistan is on number 7 place in list of countries having diabetes mellitus. It is estimated that if this trend continues than it will become number 4. Overall ratio of diabetes is that its prevalence in urban population is $22.04 \%$ and in rural area is $17.15 \%$ in Pakistan $\{5\}$. Pakistan health care system is overburdened and under resource in dealing with this situation. Considering the present situation, it demands a national effort in not only treating but more on preventing the diabetes mellitus. Many complications are associated with diabetes mellitus. Cardiovascular diseases due to diabetes is main cause of premature illness and deaths $\{6\}$. It is main cause of renal failure and blindness. It is associated with amputations due diabetic foot development.

Tuberculosis is one of the main public health problem worldwide $\{7\}$. It has been investigated that one third population of world is suffering from mycobacterium infection $\{8\}$. Patients of pulmonary tuberculosis clinically present mainly with cough, fever, hemoptysis and weight loss. Diabetes is well known risk factor for tuberculosis $\{9\}$. World health organization has classified that eight of ten countries which have highest burden of diabetes also have high burden of tuberculosis $\{10\}$. In developing countries such as Pakistan, India, Bangladesh and Brazil where tuberculosis is endemic, the burden of these two diseases and interaction between them will be more dangerous. World health organization has declared global epidemic both diabetes and tuberculosis $\{11\}$.

Relationship and association of HIV with tuberculosis is great socio economic threat and public health problem in developing countries. World health organization had estimated in 1992 that about four million population of the world had been infected by both HIV and mycobacterium tuberculosis $\{12\}$. Association between HIV and tuberculosis is evident by high incidence of tuberculosis in HIV infected patients. In developing countries where health care systems are already overburdened these two epidemics impose grave social and medical implications. 
To best of our knowledge in south Punjab of Pakistan no study had been conducted to investigate the prevalence of diabetes and HIV infection in newly diagnosed pulmonary tuberculosis patients. So this study was conducted to investigate the prevalence of these diseases in newly diagnosed pulmonary tuberculosis patients. It will provide a base for further research on this issue and will create awareness. Study done by Qiuzhen Wang et al. was taken as reference study $\{13\}$.

\section{Materials and methods}

This cross sectional study was conducted in pulmonology department Bahawal Victoria Hospital Bahawalpur. From 1 June 2018 to 1 June 2019 after taking approval from the institutional ethical committee. Total 159 newly diagnosed pulmonary tuberculosis patients were recruited by non-probability consecutive sampling. To study the prevalence of diabetes and HIV infection in non-tuberculosis group, by cluster random sampling 159 subjects were recruited from same communities as that of tuberculosis patients. Written permission of study was signed by each individual recruited in study. Exclusion criteria of study were: 1) patients with age $<18$ years of age, 2) patients who had already taken anti tuberculosis drugs, 3) patients who were known to have diabetes and HIV infection 4) patients who had any history of oncological disorder and 5) patients who had other immunosuppressive conditions. Sample size of study was calculated by using a reference study done by Qiuzhen Wang et al. for which confidence interval was taken as $95 \%$, study strength and odd ratio of diabetes in newly diagnosed pulmonary tuberculosis patients was $3.17 \%\{13\}$.

All patients were recruited from outpatient department. Detailed medical history of individual was taken and through clinical examination was conducted to record any complication of the disease and to assess any sign of other immunosuppressive disorder. Blood pressure and vitals were recorded at time of pulmonary tuberculosis patients. Blood samples were also taken to check glucose levels and hemoglobin level. Personal information like age, gender, living area, income, body mass index duration of symptoms was taken by filling the Performa.

Pulmonary tuberculosis was diagnosed according the guidelines of National Tuberculosis Program. Patients were investigated with smear examination who were suspected to have pulmonary tuberculosis. Patients who were smear negative but having clinical and radiological suspicion were also labelled as pulmonary tuberculosis after discussing it with radiologist and chest consultants.

Diabetes was diagnosed by using standard method of checking fasting plasma glucose levels as recommended by World Health Organization. Venous blood was used after overnight fasting to check plasma glucose level. Patients having plasma glucose level greater than $126 \mathrm{mg} / \mathrm{dl}$ were diagnosed as diabetics. Screening of HIV infection was done in each individual recruited in study by using ELISA method.

Data was analyzed by using SPSS volume 23. Quantitative variables like age, body mass index, plasma glucose levels and age were statistically analyzed by their mean and standard deviation and t-test was applied to check the significance. Qualitative variables like gender, living area, HIV infection, diabetes and income were statistically analyzed by frequency and percentage and chi-square test was used to check the significance. $\mathrm{P}$ value $<0.05$ was considered as statistically significant.

\section{Results}

In this study, a total number of $100 \%(n=318)$ patients were included, divided into two equal groups, $\mathbf{5 0 \%}(\mathbf{n}=\mathbf{1 5 9})$ in each i.e. PTB and non-PTB group. The Mean \pm S.D of age, BMI, FBG and hemoglobin of the patients of PTB group was $46.14 \pm 2.92$ years, $21.16 \pm 2.46 \mathrm{~kg} / \mathrm{m}^{2}, 6.02 \pm 1.15$ and $10.82 \pm 1.74 \mathrm{~g} / \mathrm{dl}$ respectively. While, the Mean \pm S.D of age, BMI, FBG and hemoglobin of the patients of non-PTB group was $48.48 \pm 3.20$ years, $23.31 \pm 2.24 \mathrm{~kg} / \mathrm{m}^{2}, 5.13 \pm 1.72$ and $12.53 \pm 1.64 \mathrm{~g} / \mathrm{dl}$ respectively. Gender distribution, in PTB group, was observed as $74.8 \%(\mathrm{n}=119)$ males and $25.2 \%(\mathrm{n}=40)$ females. While, in non-PTB group, there were $58.5 \%(n=93)$ males and $41.5 \%(n=66)$ females. There were $28.3 \%(n=45)$ and $13.2 \%(n=21)$ smokers in PTB and non-PTB group respectively. Education status of PTB group was observed as $35.2 \%(\mathrm{n}=56)$ illiterate, $39 \%$ $(\mathrm{n}=62)$ matric and $25.8 \%(\mathrm{n}=41)$ graduate or above. However, in non-PTB group, 37.1\% $(\mathrm{n}=59)$ illiterate, $28.3 \%(\mathrm{n}=45)$ matric and $34.6 \%(\mathrm{n}=55)$ graduate or above. Income level of the patients of PTB group observed as $35.2 \%(\mathrm{n}=56)$ patients had $<200000$ rupees/year and $64.8 \%(\mathrm{n}=103)$ had $>200000$ rupees/year. While, $25.8 \%$ $(\mathrm{n}=41)$ patients of non-PTB group had $<200000$ rupee/year income and $74.2 \%(n=118)$ had $>200000$ rupee $/$ year income. There were $10.7 \%(\mathrm{n}=17)$ and $4.4 \%(\mathrm{n}=7)$ patients used alcohol of PTB and non-PTB group respectively. Significant difference was found between age $(p=0.000)$, BMI $(p=0.000)$, FBG $(p=0.000)$, 
hemoglobin $(\mathrm{p}=0.000)$, gender $(\mathrm{p}=0.002)$ and alcohol consumption $(\mathrm{p}=0.034)$, in groups, except education status $(\mathrm{p}=0.090)$ and monthly income $(\mathrm{p}=0.068)$. (Table. 1$)$.

The main outcome variables of this study were HIV infection and diabetes. HIV infection was noted in $3.1 \%(n=5)$ and $1.9 \%(n=3)$ patients for PTB and non-PTB group respectively. While, $8.2 \%(n=13)$ and $4.4 \%$ $(\mathrm{n}=4)$ patients suffered from diabetes, for both the groups respectively. No significant difference was found between HIV ( $\mathrm{p}=0.474)$ and diabetes $(\mathrm{p}=0.166)$, in groups. (Table. 2$)$.

Table. 1

Characteristics of PTB and non-PTB patients

\begin{tabular}{|c|c|c|c|}
\hline Variable & $\begin{array}{c}\text { PTB } \\
(n=159)\end{array}$ & $\begin{array}{c}\text { Non-PTB } \\
(n=159)\end{array}$ & Test of Sig. \\
\hline age & $46.14 \pm 2.92$ years & $48.48 \pm 3.20$ years & $\mathrm{t}=-6.81, \mathrm{p}=0.000$ \\
\hline BMI & $21.16 \pm 2.46 \mathrm{~kg} / \mathrm{m}^{2}$ & $23.31 \pm 2.24 \mathrm{~kg} / \mathrm{m}^{2}$ & $\mathrm{t}=-8.13, \mathrm{p}=0.000$ \\
\hline FBG & $6.02 \pm 1.15$ & $5.13 \pm 1.72$ & $\mathrm{t}=-8.94, \mathrm{p}=0.000$ \\
\hline Hemoglobin & $10.82 \pm 1.74 \mathrm{~g} / \mathrm{dl}$ & $12.53 \pm 1.64 \mathrm{~g} / \mathrm{dl}$ & $\mathrm{t}=5.39, \mathrm{p}=0.000$ \\
\hline Gender & $\mathrm{M}=74.8 \%, \mathrm{~F}=25.2 \%$ & $\mathrm{M}=58.5 \%, \mathrm{~F}=41.5 \%$ & $\chi^{2}=9.56, \mathrm{p}=0.002$ \\
\hline Smoking Status & Smokers $=28.3 \%$ & Smokers $=13.2 \%$ & $\chi^{2}=11.01, p=0.001$ \\
\hline Education Status & $\begin{array}{c}\text { Illiterate }=35.2 \% \\
\text { Matric }=39 \% \\
\text { graduate or above }=25.8 \%\end{array}$ & $\begin{array}{c}\text { Illiterate }=37.1 \% \\
\text { Matric }=28.3 \% \\
\text { graduate or above }=34.6 \%\end{array}$ & $\chi^{2}=4.82, p=0.090$ \\
\hline Monthly Income & $\begin{aligned}<200000 & =35.2 \% \\
>200000 & =64.8 \%\end{aligned}$ & $\begin{aligned}<200000 & =25.8 \% \\
>200000 & =74.2 \%\end{aligned}$ & $\chi^{2}=3.33, p=0.068$ \\
\hline Alcohol Consumption & $10.7 \%$ & $4.4 \%$ & $\chi^{2}=4.51, p=0.034$ \\
\hline
\end{tabular}

Table. 2

Distribution of HIV and Diabetic in groups

\begin{tabular}{|c|c|c|c|}
\hline Variable & $\begin{array}{c}\text { PTB } \\
(\mathbf{n}=\mathbf{1 5 9})\end{array}$ & $\begin{array}{c}\text { Non-PTB } \\
(\mathbf{n}=\mathbf{1 5 9})\end{array}$ & Test of Sig. \\
\hline HIV & $3.1 \%$ & $1.9 \%$ & $\chi^{2}=0.513, \mathrm{p}=0.474$ \\
\hline Diabetic & $8.2 \%$ & $4.4 \%$ & $\chi^{2}=1.92, \mathrm{p}=0.166$ \\
\hline
\end{tabular}

\section{Discussion}

Results of study showed that prevalence of diabetes mellitus on screening in newly diagnosed pulmonary tuberculosis patients was higher (8.2\%) than in non-pulmonary tuberculosis $(4.4 \%)$ group. Similarly study also showed that HIV infection on screening was higher (3.1\%) in newly diagnosed pulmonary tuberculosis patients than in non-pulmonary tuberculosis $(1.9 \%)$ group. But this difference was statiticlly non significant with $\mathrm{P}$ value 0.474 and 0.166 .

To best of our knowledge there was no data available about prevalence of diabetes and HIV infection among newly diagnosed pulmonary tuberculosis patients as well as comparative data from non-pulmonary tuberculosis controls from the same community collected at same time. The study was designed to discover the hidden prevalence of HIV infection and diabetes mellitus in newly diagnosed pulmonary tuberculosis patients in Pakistan generally and in our local geographical area specially. Strength of this study is that, to define diabetes mellitus accurately, primary data obtained from newly diagnosed pulmonary tuberculosis patients and nonpulmonary tuberculosis group was used. While in other studies, either the prevalence of diabetes mellitus in non-pulmonary tuberculosis patients was not reported or the it was estimated from secondary data with inherent biases $\{14-15\}$. Study done by Tahir et al. showed that prevalence of diabetes mellitus among pulmonary tuberculosis patients is $14.8 \%\{16\}$. Study done by Jabbar et al. in Karachi and found that tuberculosis was ten times more prevalent in diabetic patients than in non-diabetic patients and prevalence was also increased with increase in duration of diabetes mellitus $\{17\}$. Another study carried out by Zheng et al. found that prevalence of diabetes mellitus in tuberculosis was ranging from $5 \%$ to more than $50 \%\{18\}$. Results of study done by Mukhtar et al. showed that diabetes is associated with unfavorable outcomes in pulmonary tuberculosis patients $\{19\}$. Study of Alavi et al. concluded that pulmonary tuberculosis should be considered at top of the list in 
every diabetic patients who presented with cough, sputum and dyspnea with cavitation and miliary mottling on chest $x$ ray $\{20\}$.

Many studies had been done to evaluate the prevalence and association of tuberculosis in already known HIV infected patients. But data is very limited about screening of HIV infection in newly diagnosed pulmonary tuberculosis patients. It has been noted that incidence of HIV infection is growing in our region. Study done by Giri et al. showed that $17 \%$ HIV infected patients had tuberculosis coinfection $\{21\}$. Study carried out by Chisti et al. found that pulmonary tuberculosis can be a common cause of acute pneumonia in severely malnourished or HIV infected children under five years old.

\section{Conclusion}

The results of our study revealed that on screening of newly diagnosed pulmonary tuberculosis patients with HIV infection and diabetes, their prevalence was high as compared to non-pulmonary tuberculosis group. But this difference was statistically non significant ( $P$ value 0.474 and 0.166 ).

\section{References}

1. Mahishale V, Avuthu S, Patil B, Lolly M, Eti A, Khan S. Effect of Poor Glycemic Control in Newly Diagnosed Patients with Smear-Positive Pulmonary Tuberculosis and Type-2 Diabetes Mellitus. Iran J Med Sci. 2017 Mar;42(2):144.

2. Guo SH, Chang HK, Lin CY. Impact of Mobile Diabetes Self-Care System on patients' knowledge, behavior and efficacy. Computers in Industry. 2015 May 31;69:22-9.

3. He L, Meng S, Germain-Lee EL, Radovick S, Wondisford FE. Potential biomarker of metformin action. J Endocrino. 2014 Jun 1;221(3):363-9.

4. Hussain A, Ali I. Diabetes mellitus in Pakistan: A major public health concern. Arch Pharmacy Pract. 2016 Jan 1;7(1):30.

5. Bahadar H, Mostafalou S, Abdollahi M. Growing burden of diabetes in Pakistan and the possible role of arsenic and pesticides. J Diabet Metabolic Dis. 2014 Dec 14;13(1):117.

6. Li G, Zhang P, Wang J, An Y, Gong Q, Gregg EW, et al. Cardiovascular mortality, all-cause mortality, and diabetes incidence after lifestyle intervention for people with impaired glucose tolerance in the $\mathrm{Da}$ Qing Diabetes Prevention Study: a 23-year follow-up study. Lancet Diabetes Endocrinol. 2014 Jun 30;2(6):474-80.

7. Eurosurveillance Editorial Team. WHO publishes Global tuberculosis report 2013. Eurosurveillance. 2013 Oct 24;18(43):20615.

8. Gopal R, Monin L, Slight S, Uche U, Blanchard E, Junecko BA, et al. Unexpected role for IL-17 in protective immunity against hypervirulent Mycobacterium tuberculosis HN878 infection. PLoS Pathogens. 2014 May 15;10(5):e1004099.

9. Root HF. The association of diabetes and tuberculosis. N Eng J Med. 1934 Jan 18;210(3):127-47.

10. Lönnroth K, Roglic G, Harries AD. Improving tuberculosis prevention and care through addressing the global diabetes epidemic: from evidence to policy and practice. Lancet Diabetes Endocrinol. 2014 Sep 30;2(9):730-9.

11. Kapur A, Harries AD, Lönnroth K, Wilson P, Sulistyowati LS. Diabetes and tuberculosis co-epidemic: the Bali Declaration. Lancet Diabetes Endocrinol. 2016 Jan 1;4(1):8-10.

12. Narain JP, Raviglione MC, Kochi A. HIV-associated tuberculosis in developing countries: Epidemiology and Strategies for Prevention. Tuber Lung Dis. 1992 Dec 1;73(6):311-21.

13. Wang Q, Ma A, Han X, Zhao S, Cai J, Ma Y, et al. Prevalence of type 2 diabetes among newly detected pulmonary tuberculosis patients in China: a community based cohort study. PloS One. 2013 Dec 18;8(12):e82660.

14. Restrepo BI, Camerlin AJ, Rahbar MH, Wang W, Restrepo MA, Zarate I, et al. Cross-sectional assessment reveals high diabetes prevalence among newly-diagnosed tuberculosis cases. Bull World Health Organ. 2011 May;89(5):352-9. 
15. Viswanathan V, Kumpatla S, Aravindalochanan V, Rajan R, Chinnasamy C, Srinivasan R, et al. Prevalence of diabetes and pre-diabetes and associated risk factors among tuberculosis patients in India. PloS One. 2012 Jul 26;7(7):e41367.

16. Tahir Z, Akhtar AM, Yaqub T, Mushtaq MH, Javed H. Diabetes mellitus among tuberculosis patients: a cross sectional study from Pakistan. Afr Health Sci. 2016;16(3):671-6.

17. Jabbar A, Hussain SF, Khan AA. Clinical characteristics of pulmonary tuberculosis in adult Pakistani patients with co-existing diabetes mellitus. East Mediterr Health J. 2006 Sep;12(5):522-7.

18. Zheng C, Hu M, Gao F. Diabetes and pulmonary tuberculosis: a global overview with special focus on the situation in Asian countries with high TB-DM burden. Glob Health Action. 2017 Jan 1;10(1):1-11.

19. Mukhtar F, Butt ZA. Cohort profile: the diabetes-tuberculosis treatment outcome (DITTO) study in Pakistan. BMJ Open. 2016 Dec 1;6(12):e012970.

20. Alavi SM, Khoshkho MM, Salmanzadeh S, Eghtesad M. Comparison of epidemiological, clinical, laboratory and radiological features of hospitalized diabetic and non-diabetic patients with pulmonary tuberculosis at razi hospital in ahvaz. Jundishapur J Micro. 2014 Sep; 7(9): e12447.

21. Giri PA, Deshpande JD, Phalke DB. Prevalence of pulmonary tuberculosis among HIV positive patients attending antiretroviral therapy clinic. N Am J Med Sci. 2013 Jun;5(6):367.

22. Chisti MJ, Ahmed T, Pietroni MA, Faruque AS, Ashraf H, Bardhan PK, et al. Pulmonary tuberculosis in severely-malnourished or HIV-infected children with pneumonia: a review. J Health Popul Nutr. 2013 Sep;31(3):308. 